\title{
A 6-year-old girl with ectopic cilia and hypochromic nevus
}

This article was published in the following Dove Press journal:

Clinical Ophthalmology

2 July 2014

Number of times this article has been viewed

\author{
Fabricio L da Fonseca' \\ Patricia K Yamanaka' \\ Patricia P Lima ${ }^{2}$ \\ Suzana Matayoshi' \\ 'Department of Ophthalmology, \\ ${ }^{2}$ Department of Pathology, University \\ of São Paulo Medical School, \\ São Paulo, Brazil
}

\begin{abstract}
Ectopic cilia are rare in humans. We report a 6-year-old girl with typical characteristics of ectopic cilia as described in the rare cases reported in the literature, in association with cutaneous lesions that appeared to be hypochromic nevi. This framework could be a different clinical presentation of ectopic cilia.
\end{abstract}

Keywords: ectopic cilia, cutaneous lesions, hypochromic nevus

\section{Introduction}

Ectopic cilia are very rare in humans. They are a congenital disturbance of the position of the eyelashes, which are usually on the lateral quadrant of the upper eyelid or conjunctival surface of the eyelid. The origin of these abnormally placed cilia is not clear, but a previous theory of meibomian gland substitution has been refuted and an embryologic origin suggested. ${ }^{1,2}$ In most cases, it causes no apparent medical morbidity and there is no positive family history. Treatment is surgical excision, mostly for cosmetic reasons. Here we report a case of a patient with ectopic cilia and hypochromic patches on the right arm.

\section{Case report}

A 6-year-old girl was referred for evaluation of a congenital lateral upper eyelid ectopic cilia cluster (Figure 1). On physical examination, she had hypochromic lesions on the right arm, diagnosed by the dermatology service as hypochromic nevi (Figure 1). The specimen comprised a circular $10 \times 6 \mathrm{~mm}$ portion of skin and contained a centrally placed tuft of strong and pigmented hairs. Longitudinal sections and histologic analysis showed dermal and subcutaneous pilosebaceous follicles (Figure 1A and 1B), packed in a dense fibrous tissue core (Figure 1B) extending through the eyelid from the subcutaneous area, scarcely represented in the specimen. The epidermal surface showed pores of hair follicle infundibula (Figure 1B). Well developed sebaceous lobules (Figure 1C), bulbs of pilous follicles (Figure 1D), and apocrine-lined epithelial ducts consistent with glands of Moll (Figure 1E) and associated with pilous follicles were observed. Occasional striated orbicularis muscle fibers were present in the depths of the specimen (Figure 1F), with the lowest hair bulbs (Figure 1F) superficial to them. No tarsus, meibomian gland, or lacrimal gland ducts or acini were identified.

\section{Discussion}

Congenital ectopic cilia of the eyelid skin are rare. They have been observed to protrude from the anterior surface of the eyelid skin and the posterior aspect of the tarsal plate. There are 15 cases located on the anterior surface of the eyelids. ${ }^{1,2}$ 

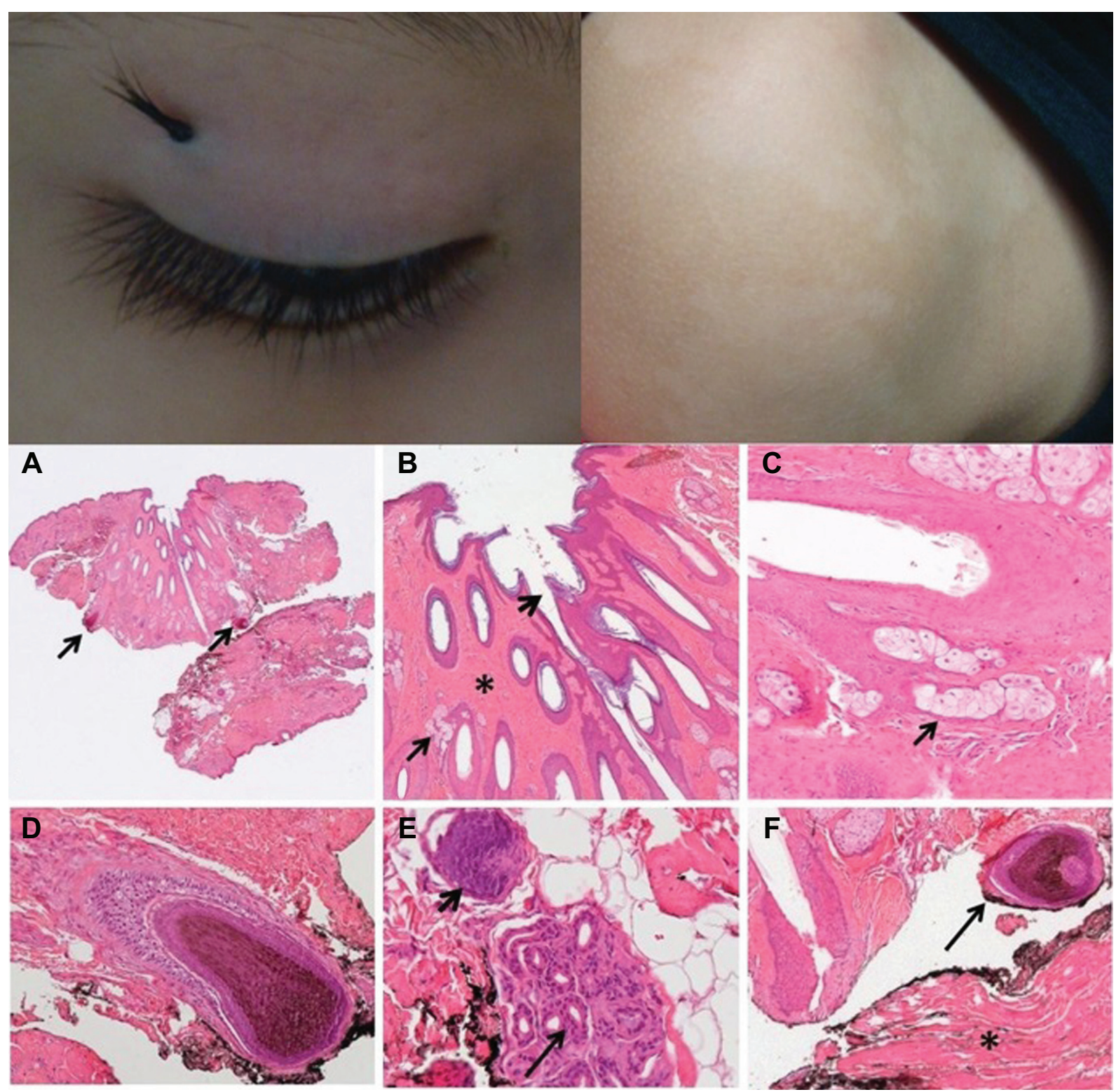

Figure I Clinical photographs of ectopic cilia (top left) and hypochromic lesions on the right arm (top right).

Notes: Histologic analysis showing (A) dermal and subcutaneous pilosebaceous follicles (arrows); (B) pilosebaceous follicles (arrows) packed in a dense fibrous tissue core $(*)$, with pores of the infundibula on the epidermal surface (arrowhead); (C) well developed sebaceous lobules (arrow); (D) bulbs of pilous follicles; (E) apocrine-lined epithelial ducts consistent with glands of Moll (arrow) and associated with a pilous follicle (arrowhead); and (F) striated orbicularis muscle fibers present in the depths of the specimen $(*)$, with hair bulbs (arrow) superficial to these muscle fibers.

Histologic examination has demonstrated the presence of apocrine and pilosebaceous glands, and there is evidence that ectopic cilia in the palpebral conjunctiva are acquired aberrant cilia, in contrast with anterior ectopic cilia, which are congenital. ${ }^{3}$

In this case, histopathologic examination of the specimen revealed the typical characteristics of ectopic cilia described in the rare cases reported in the literature. We found strong and pigmented hairs in a dense fibrous stroma associated with sebaceous and apocrine glands located in the dermis and subcutis and superficial to the orbicular muscle fibers. Importantly, ectopic cilia must be differentiated from abnormally placed hairs. As in our present case, the diagnosis of ectopic cilia is confirmed histologically by identification of sweat glands of the apocrine type attached to the follicles. ${ }^{4}$ Recent reports also underscore the importance of morphologic observation of ectopic cilia in association with lobules of sebaceous glands and apocrine glands. ${ }^{5}$ In the present case, the cilia arose from the anterior surface of the tarsal plate, being classified as anterior-type ectopic 
cilia, which are congenital, in contrast with posterior ectopic cilia that arise in the palpebral conjunctiva and are acquired aberrant cilia. $^{3}$

Although previous reports have not correlated ectopic cilia with other skin hypopigmentation disorders, it is important to note that congenital hypochromic patches (hypochromic nevi) were observed in this case.

\section{Disclosure}

The authors report no conflicts of interest in this work.

\section{References}

1. Nakra T, Blaydon SM, Durairaj VD, Shinder R. Congenital upper eyelid ectopic cilia. J Pediatr Ophthalmol Strabismus. 2011;15:48.

2. Chen TS, Mathes EF, Gilliam AE. "Ectopic eyelashes" (ectopic cilia) in a 2-year-old girl: brief report and discussion of possible embryologic origin. Pediatr Dermatol. 2007;24:433-435.

3. Hase K, Kase S, Noda M, Ohashi T, Shinkuma S, Ishida S. Ectopic cilia: a histopathological study. Case Rep Dermatol. 2012;4:37-40.

4. Dalgleish R. Ectopic cilia. Br J Ophthalmol. 1966;50:592-594.

5. Jakobiec FA, Yoon MK. Histopathologic proof for the origin of ectopic cilia of the eyelid skin. Graefes Arch Clin Exp Ophthalmol. 2013;251:985-988.
Clinical Ophthalmology

\section{Publish your work in this journal}

Clinical Ophthalmology is an international, peer-reviewed journal covering all subspecialties within ophthalmology. Key topics include: Optometry; Visual science; Pharmacology and drug therapy in eye diseases; Basic Sciences; Primary and Secondary eye care; Patient Safety and Quality of Care Improvements. This journal is indexed on

Submit your manuscript here: http://www.dovepress.com/clinical-ophthalmology-journal

\section{Dovepress}

PubMed Central and CAS, and is the official journal of The Society of Clinical Ophthalmology (SCO). The manuscript management system is completely online and includes a very quick and fair peer-review system, which is all easy to use. Visit http://www.dovepress.com/ testimonials.php to read real quotes from published authors. 